are ignored; Liverpool has only a few lines, Manchester nine pages; Portsmouth and Southampton are not mentioned; there is little of scientific relevance in the entries on Edgehill, Inverness and Wrexham among others. Inevitably, too, the bland and sweeping career-summaries fall into error at times. One amusing mistake is for Ashbourne in Derbyshire, where the entry confidently begins: "Erasmus Darwin was partial to the bottle". In fact, he was famous as a doctor for having "sobered the county of Derby", as Anna Seward put it. (Perhaps it was bottled water he was partial to?)

Although all these criticisms are valid, I liked the book. It is lively, positive and reasonably accurate. Above all, you feel that the authors have actually been there. The book abounds in strange stories,well known and little known, and I confess that I went on reading it to the end - the ultimate tribute to a guide book from a reviewer.

Desmond King-Hele is editor of Notes and Records of the Royal Society.

\section{What mad pursuit}

\section{Stuart Sutherland}

Uncovering Lives: The Uneasy Alliance of Biography and Psychology. By Alan C. Elms. Oxford University Press: 1995. Pp. 315. £18.99, \$25.

The Price of Greatness: Resolving the Creativity and Madness Controversy. By Arnold M. Ludwig. Guilford: 1995. Pp. 302. \$26.95.

PERHAPS the most disreputable branch of psychology is 'personality theory', for it is a theory that exists in name only. Despite the repeated application of factor analysis to aspects of personality, nobody can agree on what constitutes its basic traits. Nor is there even agreement that there are basic traits, because there is evidence that people act in different ways in different situations - they may be aggressive in one, timid in another; sometimes warm, sometimes cold; mean on one occasion, generous on others. The only interesting and imaginative contribution to the study of personality was made by Sigmund Freud. Unfortunately, it has no empirical validity: Freud, as he admits, talked his patients into believing what he wanted them to believe, as do his successors, including those therapists who falsely persuade their patients that they have suffered child abuse. Although, mercifully, the practice of psychoanalysis is declining in both the United Kingdom and the United States and the theory is largely ignored by psychologists, it still attracts literary magpies who use it in attempts to

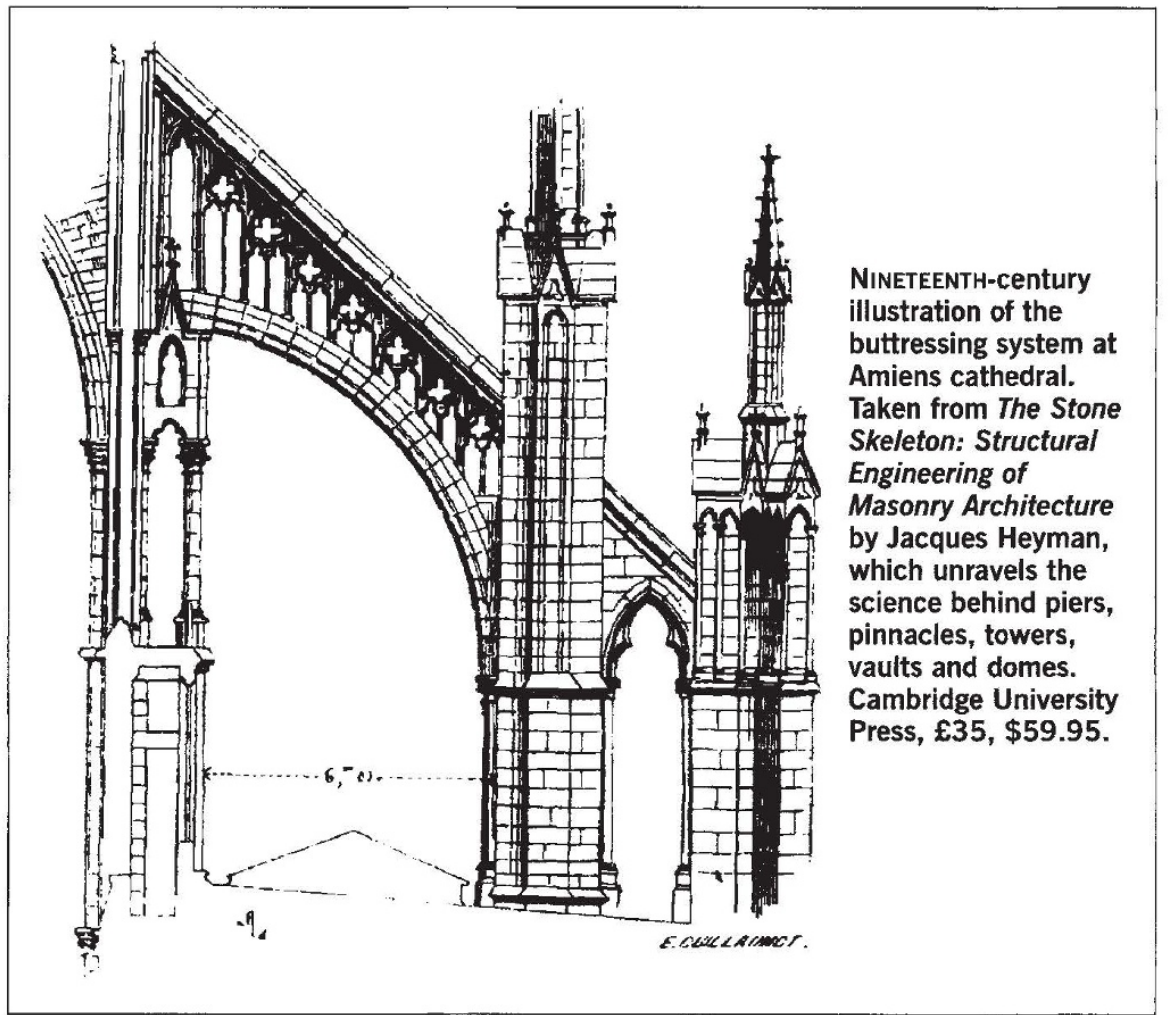

uncover the hidden meaning of texts. It is easy to see why Freud's theory is so alluring: it is based on the sex drive, and its main actors - the id, ego and superego - battle with one another in ways worthy of the Greek gods. Perhaps of most importance, no interpretation based on psychoanalysis can ever be refuted. Anything goes.

Alan Elms has chosen to apply the psychology of personality to uncovering the hidden motives and emotional influences that shaped the lives and writings of well known figures. $\mathrm{He}$ begins with some pious and extremely detailed advice to wouldbe psychobiographers (of whom the first was Freud in his notoriously inaccurate study of Leonardo da Vinci). He recommends them to focus on one aspect of their subject's life; to investigate archives, not forgetting to be nice to their curators; to interview surviving friends and relatives; to record the interviews, first making sure the tape recorder is working; and to concentrate on the meaning of contradictions in the subject's actions and writing.

He claims that modern personality theory should be used as well as psychoanalytic ideas, while taking the truth of both for granted. Almost his only nonpsychodynamic interpretation is that General Douglas Haig had an "authoritarian personality" - that is, obedience to one's superiors and insistence on obedience from inferiors, prejudice against outgroups, blaming others for one's own mistakes and so on. Unfortunately, the authoritarian personality has long since been discredited: the traits alleged to compose it simply do not go together.

Elms's free use of psychoanalysis can be illustrated by his accounts of two of his subjects. Because Isaac Asimov gave a penetrating description of agoraphobia in one of his novels, Elms thought Asimov might be agoraphobic himself and had the cheek to ask him if that were so. Asimov replied that he was not an agoraphobic, but Elms took this and further denials as evidence that Asimov must be one, concluding that he wrote science fiction to escape from himself. On the other hand, in his analysis of B. F. Skinner's motives for writing Walden Two, he put it to Skinner that it was written for therapeutic reasons to extricate himself from the midlife crisis (a concept for which there is no evidence). Skinner, possibly in order to stop Elms pestering him, civilly agreed that this was partly the reason. Elms then goes on to trace the ways in which the contents of Walden Two relieved the worries Skinner had at the time: for example, in his Utopia, children are raised by professionals, a practice that would have spared Skinner the trouble of rearing his own offspring. Psychodynamic hypotheses are confirmed both by their denial and by their acceptance.

Uncovering Lives applies the same treatment to many others, including Carl Jung and the former US president George Bush. Elms maintains that Bush began the Gulf War "to prove his masculinity to himself": he seems unaware that Bush may have had other reasons for taking this decision. Elms writes well and 
he stalks his prey in the unconscious minds of his subjects with diligence and gusto. Uncovering Lives should appeal to anyone who likes fiction, particularly detective stories.

In The Price of Greatness, Arnold Ludwig, a psychiatrist, accepts one of Elms's dicta by focusing on one feature of personality, creativity, but he takes a very different tack. Instead of examining the individual, he has undertaken an epidemiological study of 1,004 eminent Westerners who lived in this century. His sample was based on biographies of eminent people written between 1960 and 1990 excluding, one is thankful to report, famous criminals. Even so, there is a big difference between creativity and eminence, which Ludwig does not sufficiently acknowledge. He includes Marilyn Monroe, whose creativity is surely open to doubt, whereas Winston Churchill (also included), although creative, might not have become eminent had it not been for the Second World War. Moreover, luck plays a much greater part in eminence than Ludwig allows: had Roosevelt not died when he did, Truman might never have been heard of. "Full many a flower is born to blush unseen". Ludwig's study is marred by the lack of a control group of ordinary people with whom the backgrounds and characteristics of the great could be compared: in consequence he is often limited to comparing the characteristics of people eminent in different fields.

His most secure finding concerns the lifetime prevalence of mental illness in the great. Although overall it is little higher than in the population as a whole, there are striking differences between the different professions. Seventy per cent of poets had experienced depression and almost as many novelists and artists, while the prevalence of mania in these groups was about 15 times higher than in the general population. This will come as no surprise to readers of Kay Jamison's excellent book Touched with Fire (1993). Readers of Nature, however, can be reassured: eminent scientists have an exceptionally low risk of mental illness. It remains an open question whether creative authors write to ease mental conflicts or whether they become eminent because these conflicts enrich their work.

For the rest, there are few surprises in Ludwig's sample of the great. Firstborns are overrepresented, but then it has been known for some time that they tend to be more intelligent than others; writers and artists are more likely to be eccentric than are businessmen; homosexuality is common in writers. Of more interest, scientists and writers have one trait in common both tend to have been sickly or poorly adjusted when young.

Ludwig ends by allocating scores for creativity to each of his subjects. He lists

30 predictors that discriminate between those in the top and bottom quartiles and uses a regression analysis to predict in which quartile subjects lie. Surprisingly, 95 per cent of subjects were correctly placed, but because three times as many men as women were in the top quartile he could have scored 75 per cent on this criterion alone.

Moreover, he was not predicting, he was retrodicting from data already available. How far the 30 variables would predict degrees of creativity if they were applied to a different population of eminent people we do not know. Nor, despite the 55 pages of tabular data set out in an appendix, do we know the true causes of greatness. Talent and perseverance are obviously important, as is luck.

\section{Much about time in little space}

\section{Peter Landsberg}

About Time: Einstein's Unfinished Revolution. By Paul Davies. Simon Schuster/Viking: 1995. Pp. 316. \$24, £17.

Almost every possible aspect of 'time' and its associated scientific and philosophical problems are touched on in this book. An obvious omission is perhaps the question of a multidimensional time. But apart from that, every problem one might expect, as well as several one might not, is raised: cyclic time, the twin paradox of special relativity, black holes, worm holes, many-universe theories, limits to computing, the tunnel effect, naked singularities, the anthropic principle, imaginary time, advanced and retarded potentials in electromagnetism; there are even brief nods in the direction of Nietzsche, Kant and Bayes's rule of probability theory. Einstein's name is milked for all it is worth; it is used more than necessary, and there is even a one-page account of his life at the end.

So what are we to make of this, Davies's nineteenth popular science book? It must be said at once that he makes a great, and on the whole successful, effort to explain all the notions and ideas he introduces, however complicated; this is no mean achievement as he eschews all equations. Still, it struck me as a pity that the first space-time diagram appears only 17 pages after the problem of the twins has been extensively discussed. This part might have been abbreviated. In fact, quite often while reading the book I felt that it would have profited from briefer and sharper explanations.

As already pointed out, Davies covers a huge amount of material, and his references span the period from Lucretius and Plato via Eddington (1929), Tolman
The two books contrast sharply with one another. One focuses entirely on individuals, the other provides a statistical analysis of a large population. One uses theories too vague to substantiate (and sometimes already discredited), the other uses a sledgehammer approach that in the absence of any hypothesis - let alone theory - leaves the reader floundering. Nevertheless, they have two things in common. They both fail to take into account the influence of heredity on human characteristics (the evidence for which is increasingly strong) and they both read like parodies of their respective methodologies.

Stuart Sutherland is at the Laboratory of Experimental Psychology, University of Sussex, Brighton BN1 9QG, UK.
(1934) J. D. North (1965) to recent papers in Physical Review (1991, 1992), including Frank Tipler's controversial 1994 book, whose title (The Physics of Immortality) ought to have made it a bestseller (for a review see Nature 371, 115; 1994). To my considerable surprise, Davies even resurrects Herbert Dingle's Science at the Crossroads (1972), a book whose life expectancy never struck me as more than a few years. The book makes much use of the 'timewarp factor'. The budding physicist will be relieved to discover from the excellent index that this is nothing more mysterious than the unusual relativistic time dilatation.

Davies's book can be read easily and most readers will find in it matters of absorbing interest, so I can recommend it fairly strongly. Apart from the individual scientific aspects noted above, there are of course certain rather basic problems. Is time travel a phantasy? Can tachyons be ruled out? Is time an illusion of the human mind? What is responsible for the directedness of 'time'? Here the trouble is that there seem to be as yet no real answers, as the author would agree, I am sure. So at the end we are left just as puzzled about these problems as we might have been before reading the book. Indeed, some readers may have gained the insight needed to be more puzzled than they were at the beginning. As the dust jacket usefully explains: "Davies concludes that in spite of decades of progress in unravelling the mysteries of time, the revolution begun by Einstein remains tantalizingly incomplete".

Peter Landsberg is at the Faculty of Mathematical Studies, University of Southampton, Southampton SO9 5NH UK. 